\title{
Exploration on the Non-legacy Protection of Ethnic Areas under the Background of Pastoral Complex--Taking Wenchuan County of Aba Tibetan and Qiang Autonomous Prefecture as an Example
}

\author{
Jiangfeng Zhang', Xiaoying Liu ${ }^{2}$, and Li Wang ${ }^{3}$ \\ ${ }^{1}$ Southwest Minzu University, Chengdu, Sichuan, 610041, China \\ ${ }^{2}$ University of Sanya, Sanya Hainan, 572022, China \\ ${ }^{3}$ School of foreign languages, Shanxi Normal University, Linfen, Shanxi, 041000, China
}

Keywords: Idyllic complex, Non-legacy in ethnic areas, Productive protection.

\begin{abstract}
The pastoral complex is an important practical form for solving the "three rural issues" in the new era and realizing the rural revitalization strategy. As an important cultural resource in the region, the non-legacy of ethnic area is of reasonable importance to the comprehensive construction of the rural areas. The productive protection of non-legacy in ethnic areas is a suitable protection method. This paper analyzes the intangible productive protection of ethnic areas (Wenchuan County) under the background of pastoral complex, and then explores the productive protection of non-resources in ethnic areas, expecting to provide the productive protection non-legacy resources in ethnic areas with a path to use for reference.
\end{abstract}

\section{Introduction}

Urban diseases have also intensified as the urbanization rapidly develops in China. People have increasingly strong pursuit of nature and leisure, and the value and function of the countryside are being re-recognized. Rural culture is the soul of the idyllic complex, the root of rural rejuvenation, and the idyllic complex lacking the support of rural culture is unsustainable. The intangible cultural heritage of ethnic areas (hereinafter referred to as non-legacy) is an important part of the excellent culture of all ethnic groups passed down by thousands of years, and is the key to the fundamental rejuvenation of rural areas in ethnic areas. The construction of the idyllic complex has injected new vitality into the developmental protection of the non-legacy of the ethnic areas. The developmental protection of the non-legacy and the construction of the rural complex provide each other with a historical opportunity for the creative development. The non-legacy can provide cultural elements and cultural resources and enhance the cultural connotation of the idyllic complex, and the construction of the idyllic complex creates a new living space for the development of non-legacy protection. Therefore, the idyllic complex must unearth the unique local culture and outstanding non-legacy resources that have been inherited by the local generations, get rid of the stale and bring forth the fresh, promote the revitalization of local civilization, and then realize rural revitalization.

Non-legacy productive protection is one of the three major protection methods that have been proven to be effective. Since the productive protection can realize the protection and inheritance of the "active state" of the non-legacy. Therefore, since the Ministry of Culture initiated the "non-legacy" productive protection, there have been many academic papers in the academic circle to study this issue from different angles.

\section{Status Quo of Non-legacy Resources in Wenchuan County of Aba Tibetan and Qiang} Autonomous Prefecture

\subsection{Over view of Wenchuan County}

Located in the northwestern part of Sichuan Province, on the Northwestern Plateau of the Sichuan and in the southeastern part of the Aba Tibetan and Qiang Autonomous Prefecture, known as the 
"Sunshine Valley, pandas' Home, healthy Wenchuan" and has unique tourism resources, Wenchuan County has a national AAAAA-level scenic spot Wenchuan Special Tourist Area, a national AAAA-level scenic spot Daxie Cultural Tourism Zone and other scenic spots, plus neither cold winter nor hot summer, beautiful scenery and distinctive features, is one of the four major Qiang counties in the country and the national cultural and ecological experience zone.

\subsection{Overview of Non-legacy Resources in Wenchuan County}

Table 1 Summary of non-legacy and inheritors of Wenchuan County (the state level or above only)

\begin{tabular}{|c|c|c|c|c|c|}
\hline No. & $\begin{array}{c}\text { Non-legacy } \\
\text { project }\end{array}$ & Category & Level & Inheritor Status & Remarks \\
\hline 1 & $\begin{array}{l}\text { Mujiezhu and } \\
\text { Douanzhu }\end{array}$ & Folklore & Provincial(State) & Yuan Xingwen & \\
\hline 2 & Battle of the gods & Folklore & National & \begin{tabular}{|c|} 
Provincial inheritor: Ma Qianguo, male, \\
45 years old
\end{tabular} & \\
\hline 3 & Legend of Daxie & Folklore & National & Provincial inheritor: Yao Yisan & \\
\hline 4 & $\begin{array}{l}\text { Creation of the } \\
\text { World }\end{array}$ & Folklore & State & & \\
\hline 5 & $\begin{array}{l}\text { Qiang Mouth } \\
\text { Organ Playing }\end{array}$ & Traditional Music & Provincial(State) & No inheritor information found & \\
\hline 6 & $\begin{array}{c}\text { Begging for Rain } \\
\text { Song }\end{array}$ & Traditional Music & State & & \\
\hline 7 & \begin{tabular}{|c|}
$\begin{array}{c}\text { Wedding Twelve } \\
\text { Songs }\end{array}$ \\
\end{tabular} & Traditional Music & State & $\begin{array}{c}\text { Chen Pingying Wang Shilin (County } \\
\text { Level Inheritor) }\end{array}$ & \\
\hline 8 & $\begin{array}{l}\text { Picking Pepper } \\
\text { Song } \\
\end{array}$ & Traditional Music & State & Group Project, No Fixed Inheritor & \\
\hline 9 & $\begin{array}{l}\text { Sheepskin Drum } \\
\text { Dance }\end{array}$ & Traditional Dance & National & \begin{tabular}{|c|} 
National Inheritor: Zhu Jinlong \\
Provincial Inheritor: Yang Junqing Zhao \\
Banglan \\
County-level Inheritor: He Shiyong
\end{tabular} & \\
\hline 10 & Qiang Salang & Traditional Dance & Provincial & $\begin{array}{c}\text { County-level Inheritors: Chen Xiaoyan, } \\
\text { Wang Youbin and Zhao Xiaofang }\end{array}$ & \\
\hline 11 & Ritual Dance & Traditional Dance & State & & \\
\hline 12 & $\begin{array}{l}\text { Moye (Ritual } \\
\text { Dance) } \\
\end{array}$ & Traditional Dance & State & & \\
\hline 13 & $\begin{array}{l}\text { Qiang Traditional } \\
\text { Embroidery } \\
\text { Process }\end{array}$ & $\begin{array}{l}\text { Traditional } \\
\text { Craftsmanship }\end{array}$ & National & $\begin{array}{c}\text { National Inheritor: Wang Guofang } \\
\text { Provincial inheritors: Wang Sifang, } \\
\text { Chen Ping } \\
\text { County-level inheritors: Zhu Xiuqiong } \\
\text { and Yu Deshu, etc. }\end{array}$ & $\begin{array}{l}\text { Li Xingxiu (5th } \\
\text { batch of national } \\
\text { inheritors, 47) }\end{array}$ \\
\hline 14 & $\begin{array}{l}\text { Qiang Watchtower } \\
\text { Building Skills }\end{array}$ & $\begin{array}{c}\text { Traditional } \\
\text { Craftsmanship }\end{array}$ & National & $\begin{array}{l}\text { Provincial inheritor: Wang Guoyue, } \\
\text { male, } 57 \text { years old }\end{array}$ & \\
\hline 15 & \begin{tabular}{|c|} 
Qiang Sheepskin \\
Flown Production \\
Process
\end{tabular} & $\begin{array}{l}\text { Traditional } \\
\text { Craftsmanship }\end{array}$ & National & No inheritor information found & \\
\hline 16 & $\begin{array}{l}\text { Qiang Sack } \\
\text { Clothes } \\
\text { Production } \\
\text { Process } \\
\end{array}$ & $\begin{array}{l}\text { Traditional } \\
\text { Craftsmanship }\end{array}$ & Provincial & & \\
\hline 17 & Guahong Custom & Folk Custom & State & & \\
\hline 18 & $\begin{array}{l}\text { Adult Crown } \\
\text { Ceremony }\end{array}$ & Folk Custom & Provincial & & \\
\hline
\end{tabular}




\begin{tabular}{|c|c|c|c|c|}
\hline 19 & Qiang Calendar & Folk Custom & National & \begin{tabular}{|c|} 
National inheritors: Xiao Yongqing, \\
Wang Zhisheng \\
Provincial inheritors: Ren Yongxin, Yu \\
Youcheng, Yang Niandi, Yang Youyun, \\
Wang Wanlun, Wang Zhigao, Zhu \\
Guangliang and Wang Fushan \\
County-level inheritor: Zhao Guowu
\end{tabular} \\
\hline 20 & Baishi Faith & Folk Custom & State & \\
\hline 21 & Turn Mountain & Folk Custom & State & \\
\hline 22 & $\begin{array}{l}\text { Dog Sacrifice } \\
\text { Ceremony }\end{array}$ & Folk Custom & State & \\
\hline 23 & $\begin{array}{l}\text { Rain Begging } \\
\text { Ceremony }\end{array}$ & Folk Custom & State & \\
\hline 24 & Qiang Subushi & Folk Custom & State & \\
\hline 25 & Qiang Pushrod & $\begin{array}{c}\text { Traditional } \\
\text { Entertainment, } \\
\text { Acrobatics and } \\
\text { Competition }\end{array}$ & Provincial & $\begin{array}{l}\text { Provincial inheritor: Wang Qingshou, } \\
\text { male, } 42 \text { years old }\end{array}$ \\
\hline
\end{tabular}

Source of Table 1: organize and summarize according to the collected data by the author.

Since ancient times, Wenchuan County has been a region where the Tibetan, Qiang, Hui and Han nationalities integrate, and it is one of the important starting points of the Tibetan-Qiang Corridor. For thousands of years, various ethnic groups have created rich and colorful resources in the process of survival and development. These intangible resources are valuable treasures of the Wenchuan people. In the process of rural revitalization strategy and rural complex construction in Wenchuan County, these intangibles resources must play a fundamental role that cannot be ignored. It can be seen from Table 1 that Wenchuan County has five state-level non-legacy (some are jointly declared with Maoxian, Lixian and Beichuan counties), six provincial-level non-legacy, and twelve state-level non-legacy. County-level non-legacy is not included.

\section{SWOT Analysis of Non-legacy Protection in Wenchuan County under the Background of Pastoral Complex}

The idyllic complex provides a broad creative space for the revitalization of "village civilization" and provides a good inheritance platform for rural culture. With the cultural inheritance function of the rural complex, the implementation of the rural revitalization strategy will be promoted by the deeper rural culture, which is conducive to the early realization of the rural modernization and rural complex goals. In the context of the pastoral complex, the SWOT analysis model indicators of the non-legacy protection of Wenchuan County include the following four aspects: (1) Strengths: superior natural geographical environment, obvious location advantages, convenient transportation, and government policy support. (2) Weaknesses: limitation of geological conditions and the healthy ecological infrastructure is not perfect. (3) Opportunities: an increasingly large middle class, a wide-ranging high-speed rail transportation network, a large number of private capitals (4) Threats: the surrounding areas are highly competitive, and the problem of obscuring tourist destinations is prominent.

\section{Exploring the Path of Non-legacy Protection in Ethnic Areas (Wenchuan County) under the Background of Rural Complex Construction}

\subsection{Cultivate the cultural consciousness of non-genetic inheritance and protection subjects in ethnic areas, and enhance their cultural self-confidence in ethnic areas}

The non-legacy of the ethnic areas is an excellent cultural resource that has been passed down from thousands of years by various ethnic groups, and is a valuable asset possessed by all ethnic groups living in the area. Non-genetic inheritors and community members in ethnic areas are the inheritors of non-legacy in ethnic areas, and the local government is the main body of protection for 
ethnic areas. Their independent inheritance of protection awareness and ability is the key to the inheritance and protection of ethnic areas. Intangible cultural heritage is a kind of living culture. It only cultivates the cultural consciousness of the non-legacy protection subject and the inheriting subject of the ethnic minority areas, enhances their cultural self-confidence to the national intangibles of the region, and encourages them to guide them to protect the non-legacy. Economic benefits, improve the awareness of the protection of the subject.

\subsection{Screening out non-legacy projects suitable for productive protection and conduct productive protection according to local conditions and appropriate conditions}

The fundamental purpose of non-legacy protection lies in "live inheritance". The protection of productive mode should be based on the premise of respecting the original form and cultural connotation of the intangibles, and it is conducive to the lively inheritance of non-legacy. Not all non-resources can be "produced" or linked to economic benefits. In the practice of non-legacy protection in ethnic areas, it is first necessary to identify the non-legacy projects that are suitable for productive protection, and then analyze the specific problems, adapt to local conditions and appropriate conditions, and select the appropriate productive protection paths according to the characteristics of the non-legacy projects. For example, a production-oriented process-independent project can directly adopt a production-protection method that conforms to its inheritance characteristics; traditional music, dance, drama, folk art, and performances such as acrobatics and acrobatics, due to their own performance and participation, performing in festivals, tourism activities or performing stage performances, can guide visitors to participate in the experience, enhance their tourism experience and tourism quality to generate economic benefits, which is also in the category of "productive protection." However, for some non-legacy project resources such as celebrations, customs, etiquettes, which must be held at specific times and places with specific rules, they cannot be artificially changed or moved to the stage.

\subsection{Strengthen the coordination of school-area cooperation and jointly build an excellent environment for non-legacy protection in ethnic areas}

The work mode of cooperation between schools and areas, cooperation and win-win, and the protection and inheritance of non-legacy have been proved to be practical and effective, and should be advocated. The author found in Wenchuan that the work mode of school-site cooperation has not been well implemented. As a university located in Shuimo Town, Wenchuan, Aba Teachers College should play an active role in the non-productive protection of Wenchuan, but this is not the case. Aba Teachers College invested more than 6 million to purchase a set of equipment for the performance of the Qiang people's non-legacy culture, and has been idle for a long time. However, the performance of the Qiang culture in Shuimo Town of Wenchuan County is often in a state of inability to perform. Therefore, we must seize the big background of comprehensive rural construction, and strengthen school-site cooperation and jointly practice the non-legacy protection of ethnic areas under the leading role of multi-party cooperation.

\subsection{Promote the healthy eco-tourism and achieve intangible productive protection with the help of the rural revitalization strategy and the policy capital advantage of the construction of the rural complex}

The rural revitalization strategy and the integrated rural construction will undoubtedly be the starting point for the work of the party committees and governments at all levels in the future for a long period of time. The non-legacy protective protection in ethnic areas should also be based on these two major policy backgrounds as an important part of the revitalization of rural culture in ethnic areas. Wenchuan County has also been awarded a pilot project for the Qiang ecological and cultural experience zone, which is also a dual role in boosting the production protection of Wenchuan County. Wenchuan County is located in an important position in the Tibetan-Shantou Cultural Corridor. Over the years, many ethnic groups have lived together here and created a colorful multi-ethnic culture. At the same time, the flora and fauna resources of the area are very rich, with a wide variety, families are 
very comprehensive, reaching 4,000 species, and there are more than 2,000 species of animal resources, which have the dual advantages of biodiversity and cultural diversity. Wenchuan County has planted ecological agricultural products such as cherries and kiwifruit in recent years. The development of rural experience picking tourism has formed a certain brand advantage, and it has the prototype of healthy ecological tourism and rural complex. Therefore, the author believes that Wenchuan County's healthy eco-tourism is the leading industrial development path of the leading industry, which is realistic and integrated in the construction of rural complex dominated by healthy ecotourism. Suitable for productive protection, the non-legacy projects that highlight the regional national characteristics have realized the transformation and upgrading of rural tourism from the sightseeing experience to the deep experience interaction, which can bring people the real deep rural "three-life" experience and realize the rural tourism from "playing a bit" to "settle down", from "spend some money" to "deep consumption" and the experience of the unique charm of intangible ethnic areas, so as to realize the benign interaction between the non-legacy protection of the ethnic areas and the construction of the rural complex, and the win-win situation of the economic and social benefits of the national non-legacy.

\section{Acknowledgement}

This research was financially supported by the National Social Science Key Project: Jiang Bin, Research on the Protection Path of Traditional Villages in Southwest Ethnic Areas in the Process of New Urbanization (Grant NO.15AMZ010); and supported by 2018 Aba Prefecture Social Science Special Fund Project: Research on Non-genetic Conservation and Development and Utilization in Ethnic Areas under the Background of Rural Revitalization Strategy_-Taking Wenchuan County of Aba Prefecture as an Example (Grant NO.ABKT2018068); and also supported by Southwest University for Nationalities, 2018 Graduate “Innovative Research Projects” Funded PhD Project: Protection and Development of Ethnic Areas from the Perspective of Tourism Empowerment (Grant NO.CX2018BS16).

\section{References}

[1] Tian Zhaoyuan. Economic Folklore: Exploring the Trajectory of Identity Economy_-Also on the Essential Attribute of Non-legacy Production Protection, Journal of East China Normal University (Philosophy and Social Sciences Edition), 2014(2).

[2] Xu Yiyi. The Role of Inheritors in the Productive Protection of Intangible Cultural Heritage, Guizhou Social Sciences, 2012(12). 